\title{
BRDF Model of Mars Simulation Soil and Its Comparison with BRDF of Earth Sand
}

\author{
Yu-Feng Yang, ${ }^{1,2}$ Xiang Han $\mathbb{D}^{1},{ }^{1}$ Ming-Bo Jiang, ${ }^{3}$ An-Li Han, ${ }^{1}$ and Wen-Shuai Li ${ }^{1}$ \\ ${ }^{1}$ School of Automation \& Information Engineering, Xi'an University of Technology, Xi'an 710048, China \\ ${ }^{2}$ Shaanxi Civil-Military Collaboration Key Laboratory of Intelligence Coordination Networks, Xi'an University of Technology, \\ Xi'an 710048, China \\ ${ }^{3}$ Beijing Institute of Applied Meteorology, Beijing 100000, China
}

Correspondence should be addressed to Xiang Han; 852432328@qq.com

Received 24 September 2020; Revised 10 November 2020; Accepted 5 March 2021; Published 16 March 2021

Academic Editor: Heng Liu

Copyright (c) $2021 \mathrm{Yu}$-Feng Yang et al. This is an open access article distributed under the Creative Commons Attribution License, which permits unrestricted use, distribution, and reproduction in any medium, provided the original work is properly cited.

\begin{abstract}
In this paper, a seven-parameter BRDF model with double-peak characteristic, which could fit double-peak data, was adopted to fit the BRDF of Mars simulation soil. At the same time, the three-dimensional figure of the original data of the sample and the three-dimensional curve of the fitted curve were given. The results proved that the model worked well for this type of data. In addition, the experimental data of four kinds of earth sand samples with different roughness were also fitted and analyzed. It was found that the model still had a good fitting effect on such data. At last, the Mars simulation soil and the four kinds of earth sand samples with different roughness were compared horizontally and vertically. Moreover, the double-peak characteristics and other properties of the Mars simulation soil and the earth sand were analyzed under the same and different roughness.
\end{abstract}

\section{Introduction}

In recent years, human has never stopped exploring Mars. The Mars soil is the most important material on the Mars surface. It is an extremely complex chemical material, which is formed by the combination of various factors such as animals and plants, climate, wind, topography, solar radiation, and crustal movement on the surface of the planet. In 2016, Liu and Jiang [1] proposed a simulation model of Martian soil mechanics parameters based on the simulating model of the monthly lunar soil mechanics parameters, which proposed three types of simulated Martian soil mechanics parameters, the fine-grained, the moderately dense, and the hard-type, which covered surface soil types from low bearing capacity to hard ground on the Mars surface. It provided technical support for simulating the preparation of Martian soil, establishing the mechanics model of the Martian wheel, and designing the planetary vehicle walking system and ground traction performance test. In 2016, Dang and Chen [2] analyzed the physicomechanical characteristics of the existing Martian soil and the simulated Martian soil. Further, they combed out the parameters of the physical and mechanical properties of Martian soil. The physical and mechanical properties of the Martian soil directly affect the lander's landing buffer. The design of the landing system, the rover vehicle mobile system, and so forth can provide reference for the development of China's Mars probe. In 2017, Han et al. [3] discussed the influence of the soil type and compactness, the impact height and the footpad diameter on the impact depth, the acceleration, and impact peak during the lander impact on the Mars surface. The analysis results showed that the soil type and compactness had the greatest impact on the impact depth, followed by the footpad diameter, and the impact of the impact height is the smallest. In addition, the soil not only provides the necessary nutrients and water for plants but also is the habitat for the soil animals to live in. The formation of the soil is inseparable from the activities of the living things. Therefore, the study of the Bidirectional Reflectance Distribution Function (BRDF) characteristics of Martian soil not only helps to infer the factors of Martian soil surface radiation distribution, such as soil roughness and particle size, but also estimates some key 
properties of Martian soils and further reverses the physical and chemical properties of Martian soil, such as the water content, the organic carbon content, and the analysis of some characteristics of the Martian soil [4-6] and even speculates whether there is life on Mars. However, the BRDF of the soil is one of the difficulties in current quantitative remote sensing research. Its research is helpful for the remote sensing interpretation, the inversion of features, and the improvement of optical characteristic inversion accuracy. At the same time, the study of the BRDF characteristics of the soil can provide the background reference for the study of vegetation canopy spectrum. The directional distribution of soil reflectivity also carries information such as soil moisture, organic matter content, and mineral content. Therefore, the study of the soil BRDF characteristics has the important theoretical and practical research value for quantitative remote sensing of soil and vegetation [7-9] and has the positive meaning for the further exploration on Mars in the future.

In 2006, Wu [10] proposed a new method of solar ray stripping. From the perspective of the multiangle remote sensing and the polarized light remote sensing, the polarization characteristics were found as a function with the solar elevation angle and doing polarization stripping of glare using the characteristic of polarization azimuth and polarization at Brewster's angle, which provided a technical reference for the effect of water color remote sensing to eliminate solar flare. Then a new soil polarization BRDF model was established to improve the classification accuracy and inversion accuracy of the soil. In 2010, Cierniewski et al. [11] found that the soil reflectance spectra of the studied surface, which is illuminated by the direct sunbeams, were clearly convex with distinct absorption features. Furthermore, the soil normalized reflectance spectra were used to distinguish and analyze the subtlety of the shaded soil spectra shape. They found that the depressions caused by the absorption features of $\mathrm{O}_{2}$ and $\mathrm{H}_{2} \mathrm{O}$ were contained in the atmosphere above the directly illuminated soil fragments and transformed into peaks, if the same soil was deeply shaded. In 2011, Liu et al. [6] measured the spectral reflectance distribution function (spectral polarimetric BRDF) of the soil in the visible band $(400-720 \mathrm{~nm})$. The relationship between variation of spectral polarimetric BRDF (pBRDF) with observing angle and wavelength was analyzed. By comparing predicted value with measured value, it was known that the intensity model used in this paper can describe the characteristics of the soil with great accuracy, so it was possible to analyze the trend of soil model parameters according to the established model. Under the certain conditions, it may reflect some characteristics of the soil itself. The relationships between the degree of polarization and detection angle, the wavelength, and the intensity component for the soil were also analyzed. It had the theoretical significance for the study of polarization properties of the soil. In 2012, Croft et al. [12] used regression analysis of AM against a geostatistical-derived value of soil surface roughness (sill variance) to test the ability of the AM for description of surface roughness for all soil types. The results showed that the use of a directional AM index dramatically improved the relationship with sill variance compared to the use of a single viewing angle $\left(R 2=0.68\right.$ at $\theta \mathrm{r}=40^{\circ} ; R 2=0.88$ $(\mathrm{AM})$ ), demonstrating the great potential of this approach for compensating for spectral differences between different soil types. The results provided an empirical and theoretical basis for the future retrieval of spatially distributed assessments of the soil surface structure across larger spatial extents. In 2014, Wang et al. [13] found that the soil surface reflectance was generally higher at the backscattering view zenith angles and decreased continuously to forward scattering view zenith angles in the light principal plane, regardless of the wavelength. Higher soil surface reflectance was observed at higher illumination and viewing zenith angle combinations. For both soil surface roughness categories, the BRDF exhibited a greater range of values in the near-infrared than at the visible wavelengths. This research enhanced our understanding of soil BRDF for various soil roughness and illumination conditions. In 2016, Huang [14] combined the hybrid pixel decomposition technique with the BRDF nuclear drive model to realize the remote sensing inversion of the hybrid pixel in the narrow-band albedo; then the $6 \mathrm{~S}$ model was used for the radiation simulation, and the energy was narrowed. The band albedo was converted to a wide band. The verification results showed that, compared with the traditional hypothesis that the surface is the albedo calculated under the Lambertian condition, this method can improve the inversion accuracy of the surface albedo based on prior knowledge. In 2017, Liu [15] found that, due to mutual shielding between the surface particles of the soil, soil BRDF increased with the increase of the zenith angle of the light source. The change was related to the wavelength. When the observed azimuth angle was different, the soil BRDF in the backscattering direction was the highest, and the soil BRDF in the forward scattering direction was the smallest. In the range of $400 \mathrm{~nm} \sim 1400 \mathrm{~nm}$, when the soil water content was less than the field water holding capacity, the soil BRDF value decreased with the increase of water content; when the soil water holding capacity was larger, the soil BRDF value increased with the increase of water content. However, in the range of $1400 \mathrm{~nm} \sim 2400 \mathrm{~nm}$, there was no obvious change in soil BRDF caused by different soil water content under different observation positions. In addition, Martian soil is not only the main target of surface exploration activity of Mars but also one of the important factors to be considered in the design of surface detectors. Simulations of similar Martian soils help us understand the characteristics of Martian soil, which provides feasibility and reference for our next use of Earth's sand to experimentally analyze some of the characteristics of Martian soil [16-19].

The study of the soil BRDF characteristics is significant not only for the Martian exploration and the concerning research activities but also for the development of quantitative and soil remote sensing technology, which is the key of the Martian soil water content survey, the surface temperature, the surface albedo, and so forth. In addition, it is also an important factor that must be considered in the global ground remote sensing research [20-24]. The surface roughness is one of the main factors affecting the emission and scattered radiation of the soil in the microwave band. It 
plays an important role in the research and application of active and passive microwave remote sensing. However, the microwave backscattering is also affected by the factors such as the dielectric properties and the penetration depth. Therefore, it is often difficult to consider the surface roughness of the medium alone in microwave remote sensing applications. Consequently, it brings certain difficulties to parameter estimation and inversion. Moreover, in the visible and the near-infrared bands, the roughness is one of the important structural parameters of the soil surface. It directly affects the BRDF characteristics of the soil. This paper uses the BRDF model to compare and analyze the characteristics of the simulated Martian soil and the four different roughness earth sand samples.

\section{Soil Seven-Parameter BRDF Model}

For the BRDF of Martian soil, as the incident angle increases, the BRDF gradually shows two peaks. As shown in Figure 1(d), the double-peak characteristic of the data can be clearly seen when the incident angle is $60^{\circ}$. Figure 2 shows the original data of the Martian soil BRDF at $650 \mathrm{~nm}$. It can be seen more clearly from Figure 2(d) that the data has two peaks. The traditional five-parameter and the six-parameter BRDF model [21] cannot accurately fit this type of data.

In this paper, a BRDF seven-parameter semiempirical statistical model suitable for the double-peak characteristic of target data is used [25]:

$$
\begin{aligned}
f_{r}\left(\theta_{i}, \theta_{r}, \phi_{r}\right)= & k_{a} \exp \left[k_{1}\left(1-\cos \gamma_{1}\right)^{a}\right] \\
& +k_{b} \exp \left[k_{2}\left(1-\cos \gamma_{2}\right)^{b}\right]+\frac{k_{c}}{\cos \theta_{i}},
\end{aligned}
$$

where

$$
\left\{\begin{array}{l}
\cos ^{2} \gamma_{1}=\frac{\cos \theta_{i} \cos \theta_{r}-\sin \theta_{i} \sin \theta_{r} \cos \left(\phi_{r}-\phi_{i}\right)+1}{2}, \\
\cos ^{2} \gamma_{2}=\frac{\cos \theta_{i} \cos \theta_{r}+\sin \theta_{i} \sin \theta_{r} \cos \left(\phi_{r}-\phi_{i}\right)+1}{2} .
\end{array}\right.
$$

Equation (1) has two parts. The first part represents the specular reflection component; $k_{a}$ and $k_{b}$ are the mirror reflection coefficients. The second part represents the diffuse reflection component $k_{c}$, which is the diffuse reflection coefficient. $\exp \left[k_{1}\left(1-\cos \gamma_{1}\right)^{a}\right]$ and $\exp \left[k_{2}\left(1-\cos \gamma_{2}\right)^{b}\right]$ represent reflection function, which can be used to fit data with double peaks. When the data has only one peak, $k_{1}$ and $k_{2}$ are equal, which means that the two peaks are coincident. $\theta \mathrm{i}$ and $\theta \mathrm{r}$, respectively, represent incident zenith angle and scattering zenith angle. $\phi_{i}$ and $\phi_{r}$, respectively, represent incident azimuth angle and scattering azimuth angle. $k_{a}, k_{1}$, $a, k_{b}, k_{2}, b$, and $k_{c}$ are the parameters to be determined.

This model is used to fit and analyze the BRDF data of the five different soil samples as follows. The roughness of the five samples is described by the roughness of the sand grains. Sample 1 is the soil of Mars, the mesh number of the sand in sample 2 is 75 , and the corresponding aperture is $0.2 \mathrm{~mm}$; the mesh number of the sand in sample 3 is 45 and the corresponding aperture is $0.4 \mathrm{~mm}$; the mesh number of the sand in sample 4 is 30 and the corresponding aperture is $0.6 \mathrm{~mm}$; the mesh number of the sand in sample 5 is 24 and the corresponding aperture is $0.8 \mathrm{~mm}$.

\section{Soil BRDF Model Verification}

3.1. Verification of Mars Soil BRDF Model. In this paper, the seven-parameter BRDF model is used to fit the BRDF data of the Martian soil sample (sample 1). There are 4 sets of data in the sample, which are fitted one by one to analyze the BRDF characteristics of the Martian soil. The following is a fitting analysis of a single curve with a wavelength of $650 \mathrm{~nm}$.

Figure 3 shows the experimental data of the Martian soil (sample 1) and the fitted results of the model. The incident angles are, respectively, $0^{\circ}, 30^{\circ}, 45^{\circ}$, and $60^{\circ}$, and the wavelength is $650 \mathrm{~nm}$. As Figure 3 shows, the fitting effect of the model is good, especially the experimental data of the sample with double peaks as shown in Figure 3(d); it can be seen that the fitting curve can be perfectly fitted to the two peaks of the original data. Figure 4 shows a fitted 3D graph of the Martian soil.

As shown in Figure 4, it can be seen that the model has a good overall effect on the Martian soil, which is basically consistent with the original soil data and has achieved the expected goal.

\subsection{Comparison of BRDF between Martian Soil and Earth} Sand. The BRDF data of four earth sand samples with different roughness (sample 2 to sample 5) are analyzed. Figures 5-8 show the 3D figures of the original data from sample 2 to sample 5 .

The fitted curves of Mars soil BRDF and Earth sand BRDF are compared and analyzed. Figure 9 shows the fitted curves of the five samples with the same wavelength. Sample 1 and sample 2 have the same roughness, and the roughness of sample 2 to sample 5 gradually grows.

It can be seen from Figure 9 that the BRDF peak of the Martian soil sample is more prominent, and the double-peak effect is extremely obvious. The peak of BRDF in the sand sample is relatively flat, and the double-peak effect is relatively poor. With the increase of roughness, the peak value of BRDF in sand and the double-peak effect are gradually reduced. As far as the fitting effect is concerned, the model has a good fitting effect on each of the above samples, especially when the sample BRDF data has a double-peak characteristic. It can perfectly solve the problems which cannot be solved by the five-parameter and the six-parameter model. The fitting diagram of five-parameter and six-parameter model can only fit a single peak but not a double peak. However, the sevenparameter model can fit the double peak very well. The $3 \mathrm{D}$ fitted graph of the earth sand sample (sample 2 to sample 5) is given, as shown in Figure 10-13.

As is shown above, the model has a good fitting effect on the earth sand, which is basically consistent with the original soil data and has achieved the expected goal. Then we 


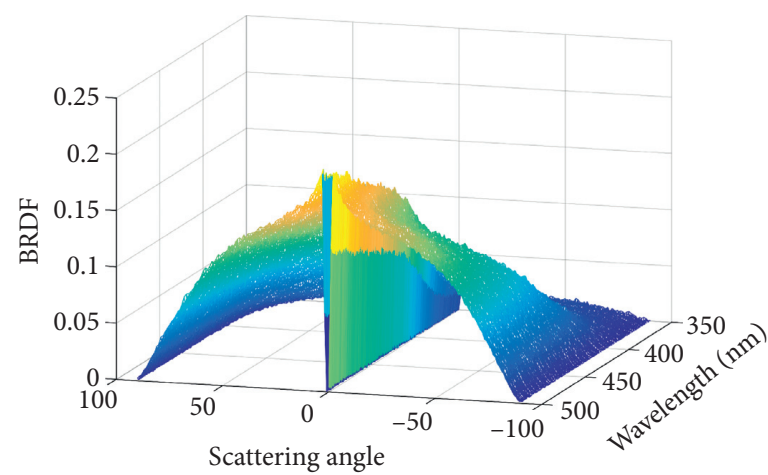

(a)

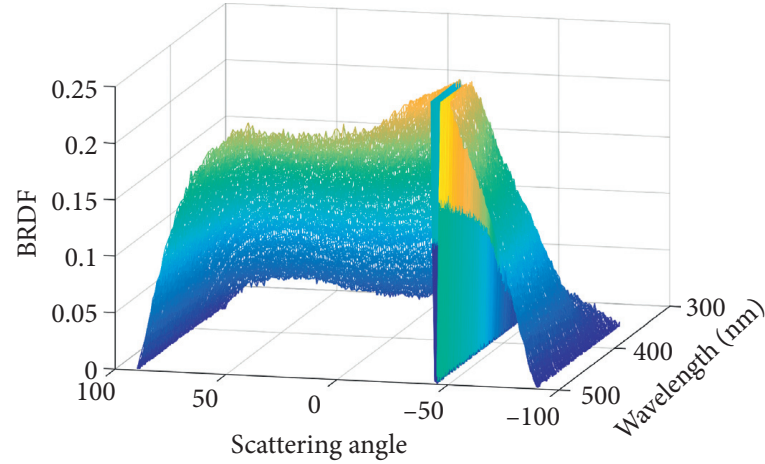

(c)

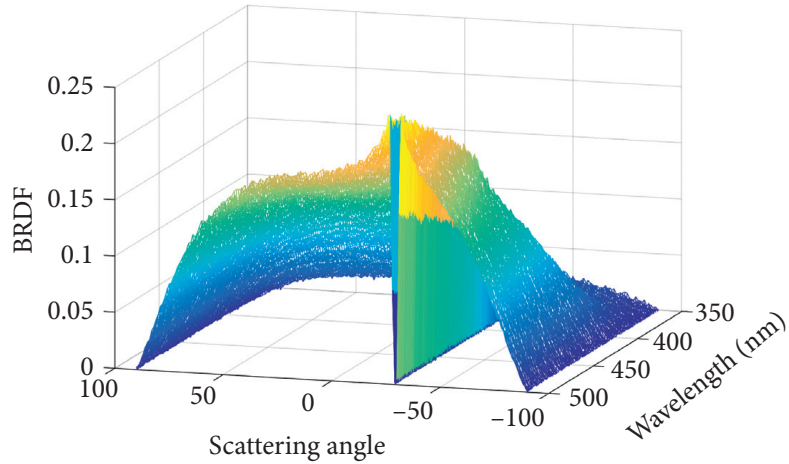

(b)

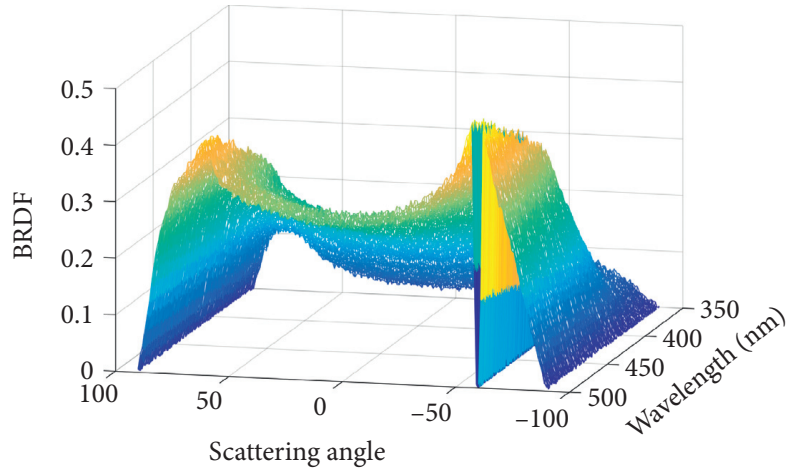

(d)

Figure 1: 3D graph of Martian soil BRDF. (a) 3D data of $0^{\circ}$ incident angle; (b) 3D data of $30^{\circ}$ incident angle; (c) $3 \mathrm{D}$ data of $45^{\circ}$ incident angle; (d) original data at $60^{\circ}$ incident angle.

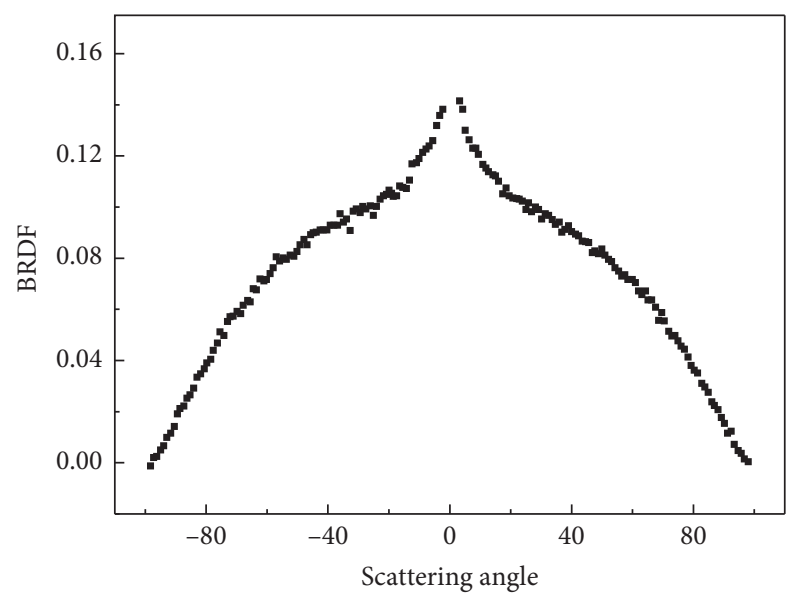

Experimental data

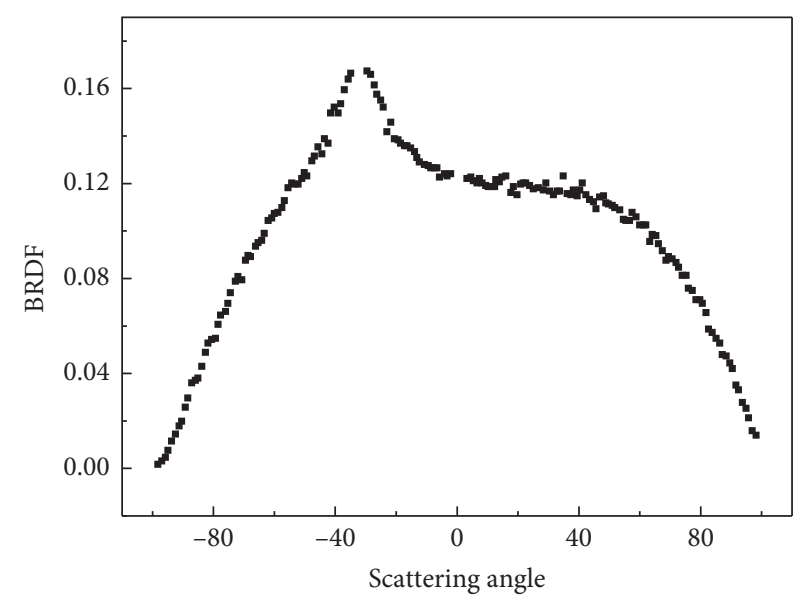

- Experimental data

Figure 2: Continued. 


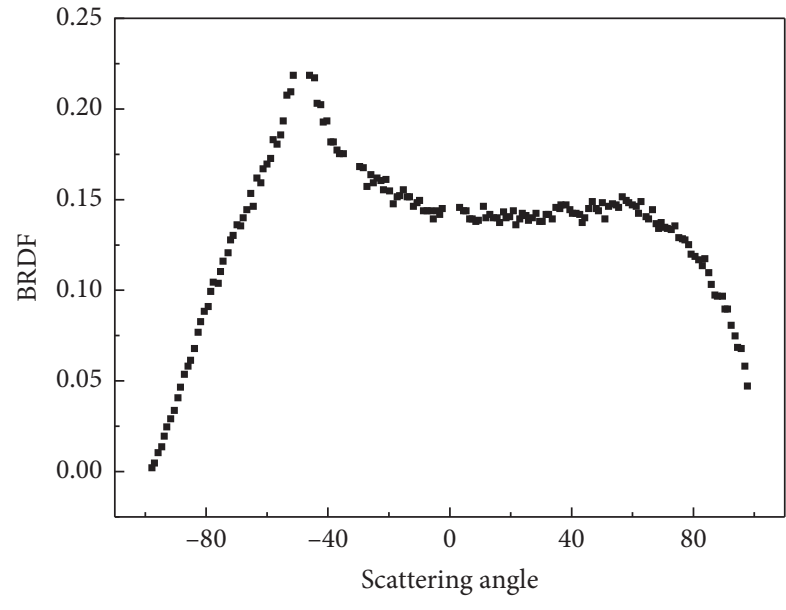

Experimental data

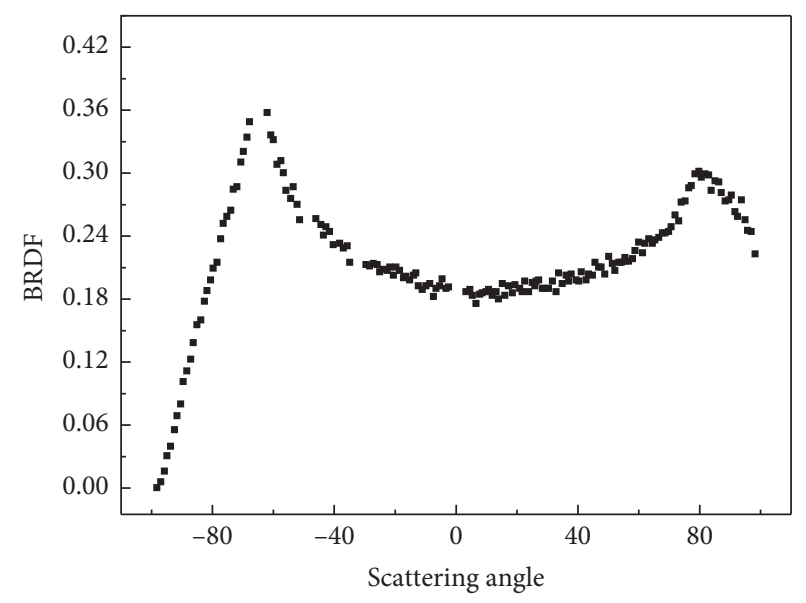

Experimental data

(c)

(d)

Figure 2: BRDF data of Martian soil. (a) Original data at $0^{\circ}$ angle of incidence; (b) original data at $30^{\circ}$ angle of incidence; (c) original data at $45^{\circ}$ angle of incidence; (d) $3 \mathrm{D}$ data of $60^{\circ}$ incident angle.

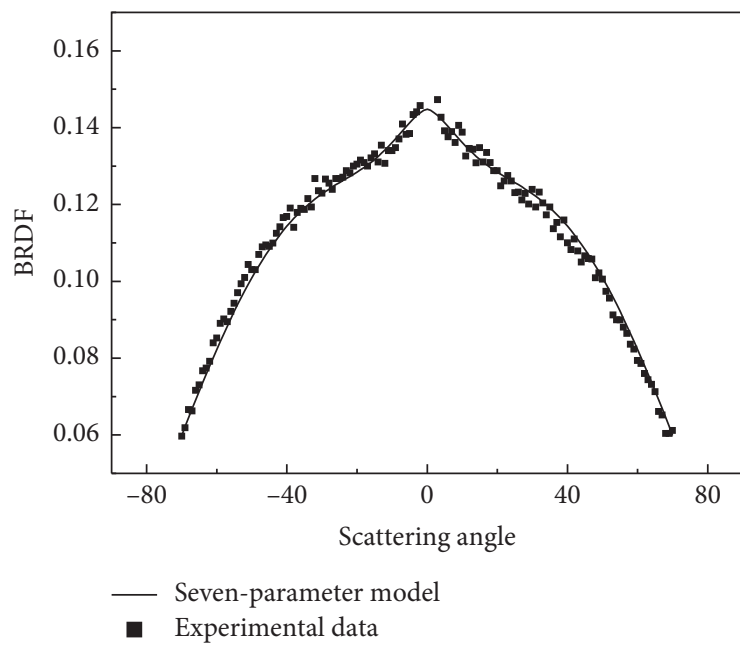

(a)

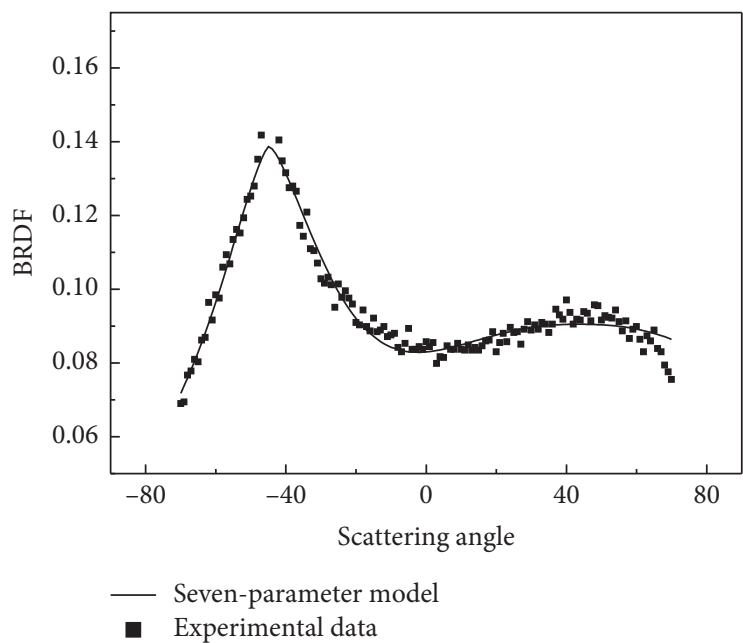

(c)

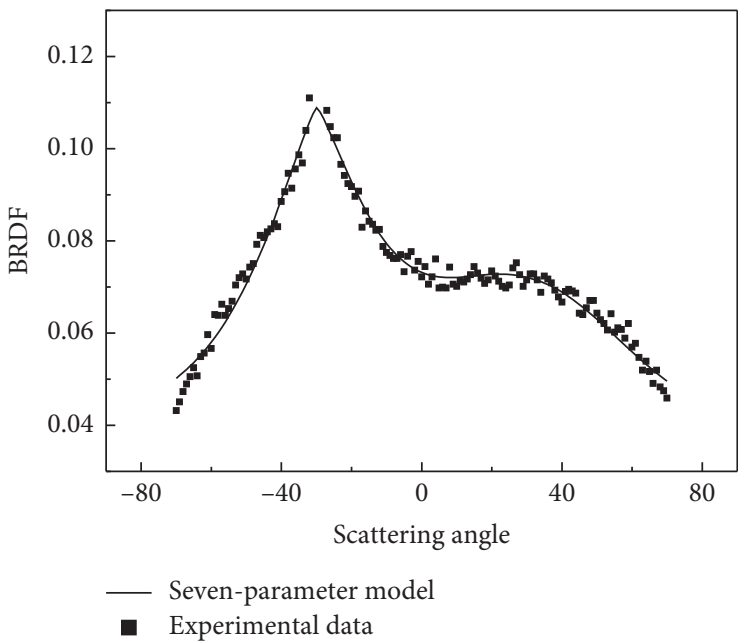

(b)

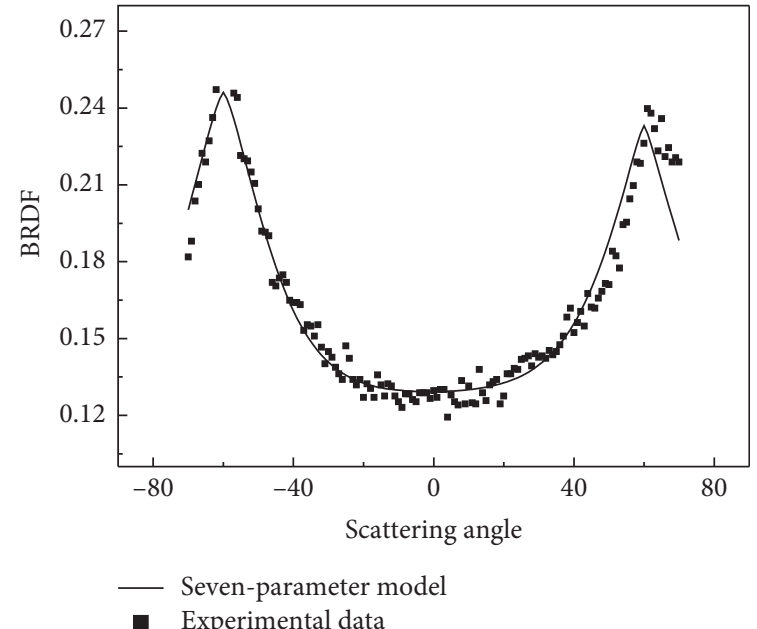

(d)

Figure 3: Fitted curve of Martian soil. (a) Fitted curve of $0^{\circ}$ incident angle; (b) fitted curve of $30^{\circ}$ incident angle; (c) fitted curve of $45^{\circ}$ incident angle; (d) fitted curve of $60^{\circ}$ incident angle. 


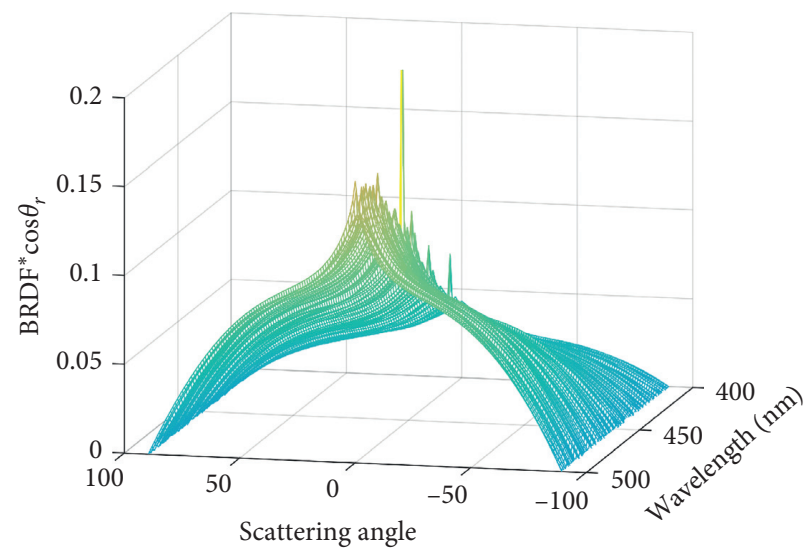

(a)

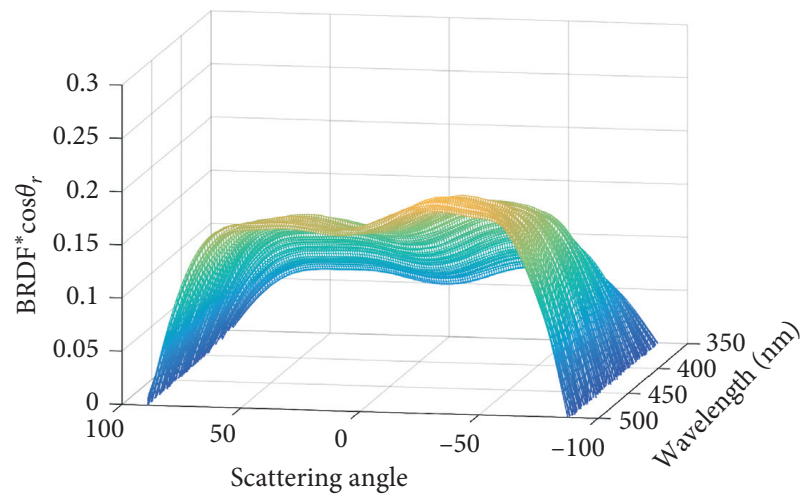

(c)

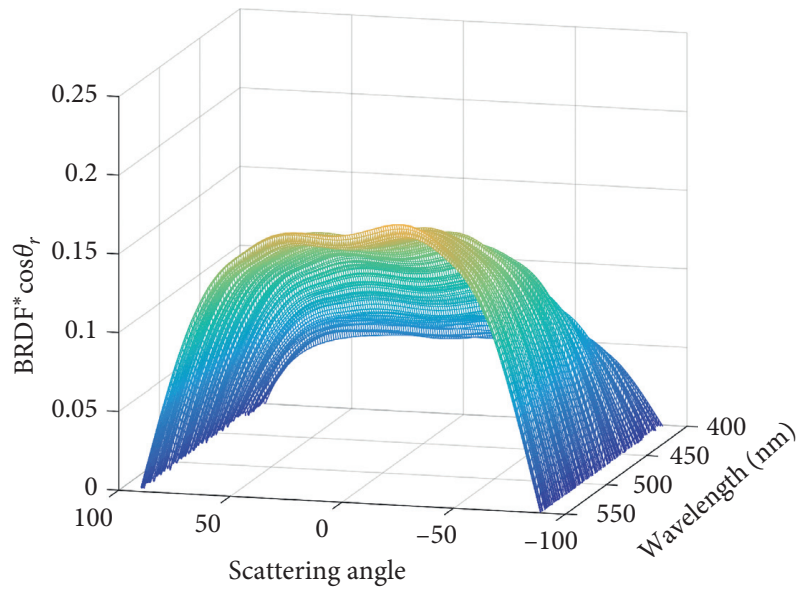

(b)

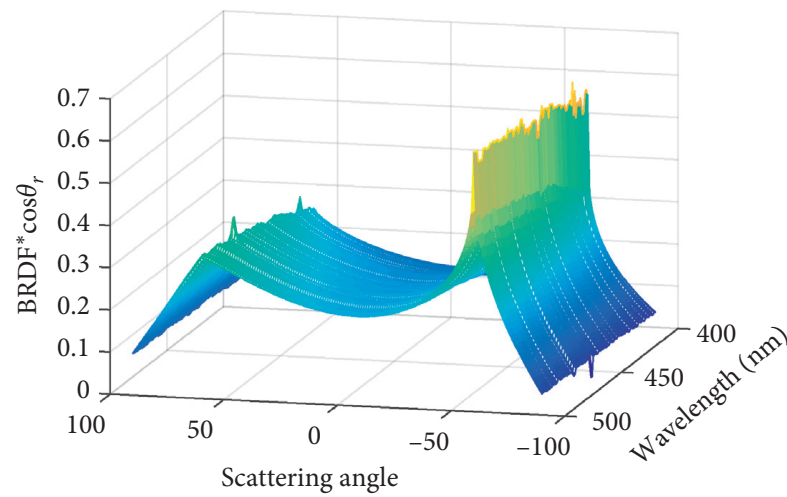

(d)

Figure 4: Fitted 3D graph of the Martian soil. (a) Fitted 3D graph of the $0^{\circ}$ incident angle; (b) fitted 3D graph of the $30^{\circ}$ incident angle; (c) fitted 3D graph of the $45^{\circ}$ incident angle; (d) fitted 3D graph of the $60^{\circ}$ incident angle.

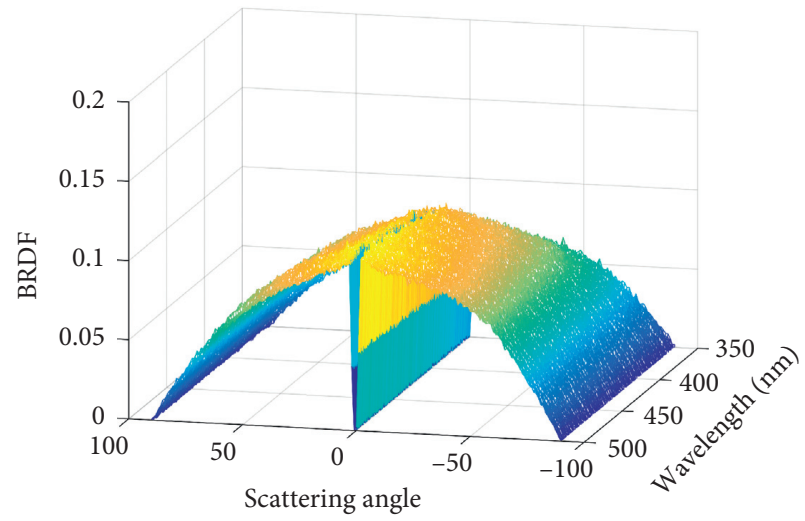

(a)

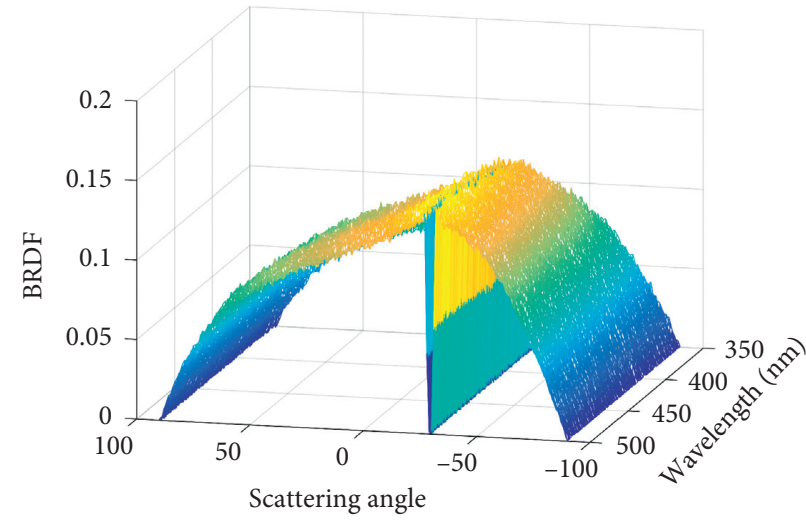

(b)

FIGURE 5: Continued. 


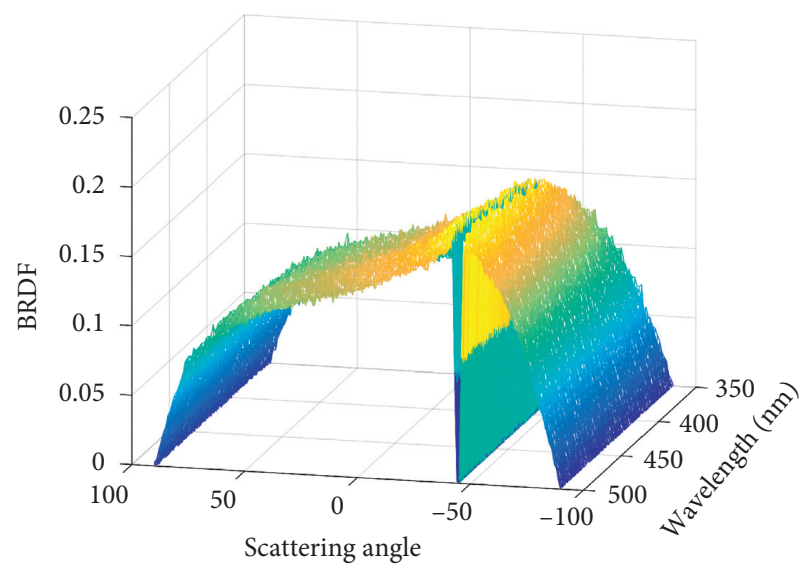

(c)

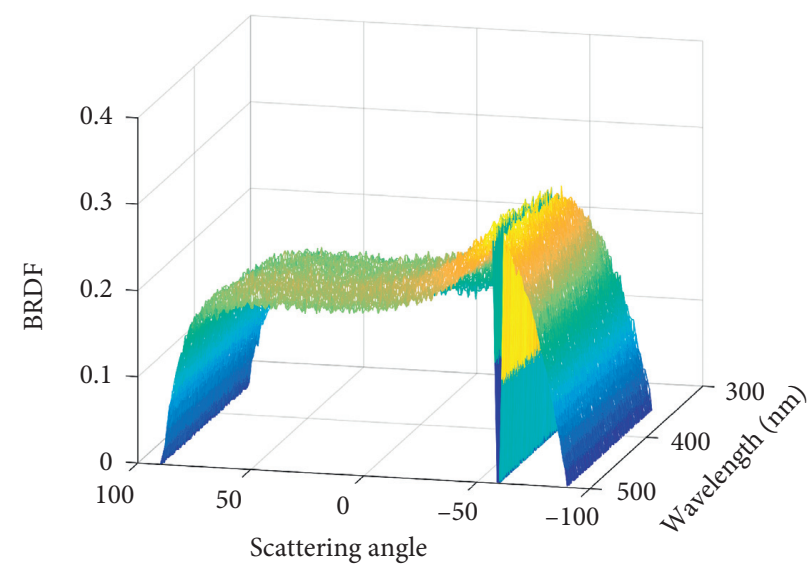

(d)

Figure 5: 3D graph of sample 2. (a) 3D data of $0^{\circ}$ incident angle; (b) $3 \mathrm{D}$ data of $30^{\circ}$ incident angle; (c) $3 \mathrm{D}$ data of $45^{\circ}$ incident angle; (d) $3 \mathrm{D}$ data of $60^{\circ}$ incident angle.

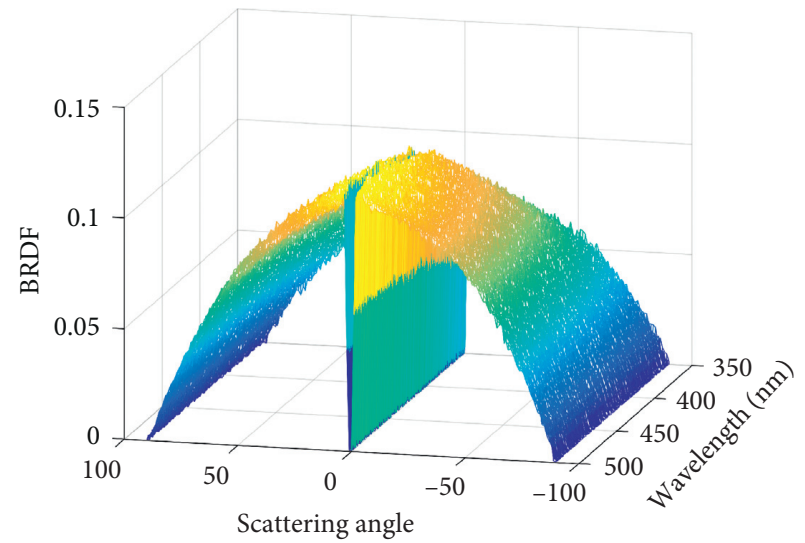

(a)

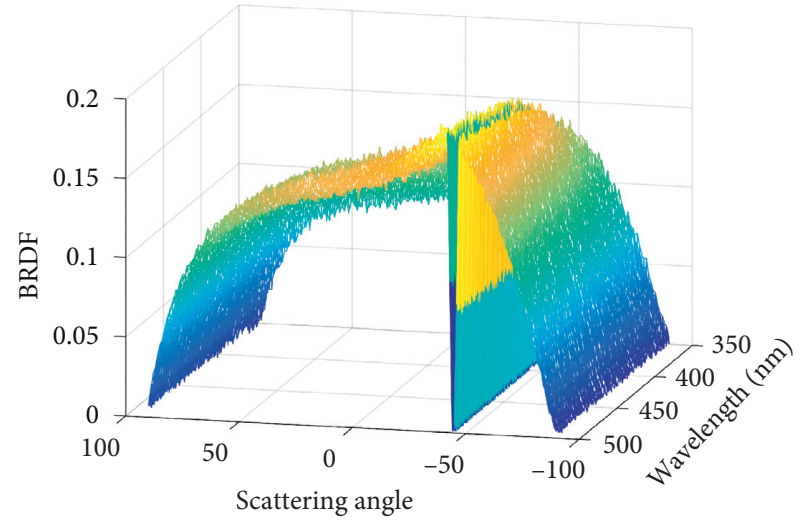

(c)

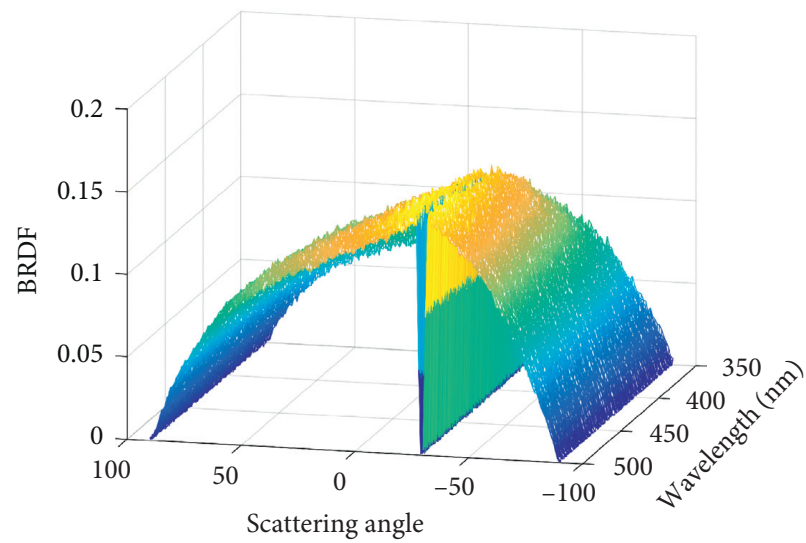

(b)

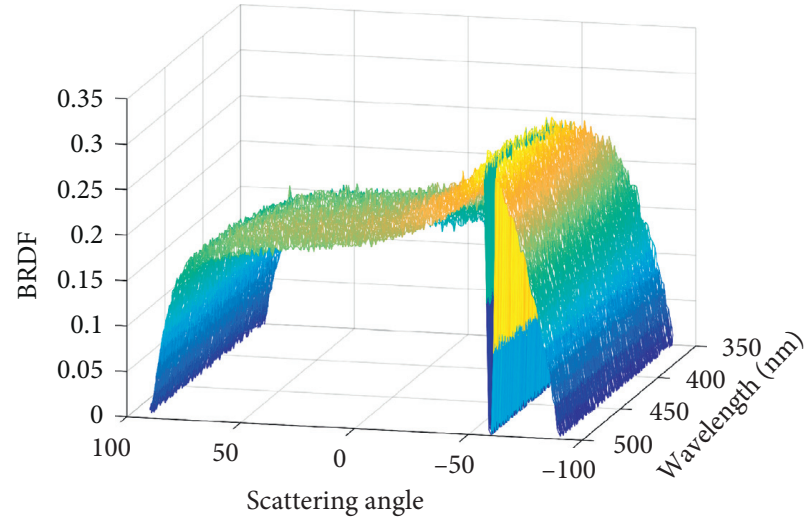

(d)

Figure 6: 3D graph of sample 3. (a) 3D data of $0^{\circ}$ incident angle; (b) 3D data of $30^{\circ}$ incident angle; (c) 3D data of $45^{\circ}$ incident angle; (d) 3D data of $60^{\circ}$ incident angle.

compare the model parameters with $60^{\circ}$ incident angle of curves, which has the most obvious double-peak characteristic in sample 2 to sample 5 .

From Table 1, it can be seen that, with the increase of soil roughness, $k_{a}, k_{2}$ in the model parameters gradually decreases, and $k_{1}$ gradually increases, which means that the two double peaks corresponding to the fitted curve are slowly decreasing, while the two sides of peak value are also steeper and steeper. The other four parameters $a, k_{b}, b$, and $k_{c}$ are not much changed. The model has small fitting errors for the five sets of data; it can be seen that the fitting effect of the model is better. 


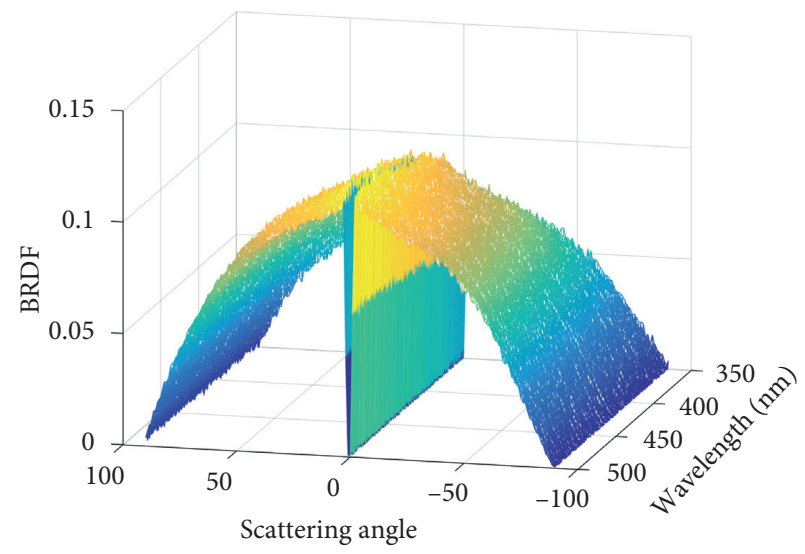

(a)

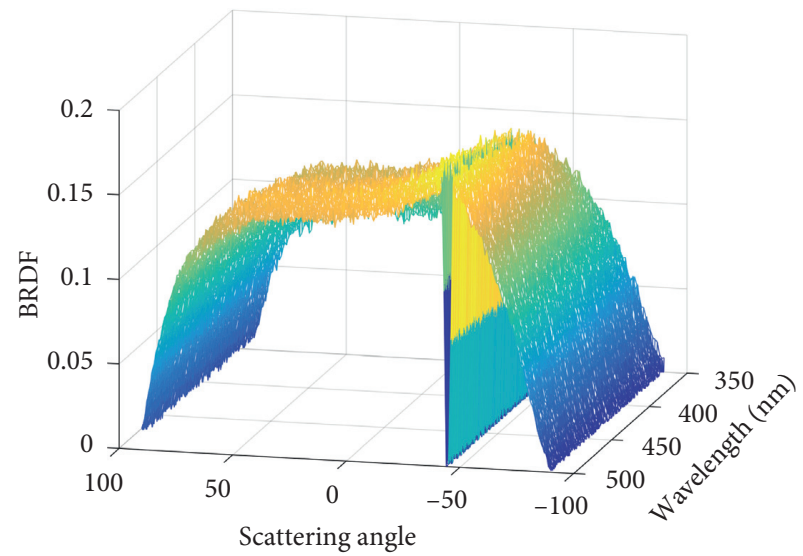

(c)

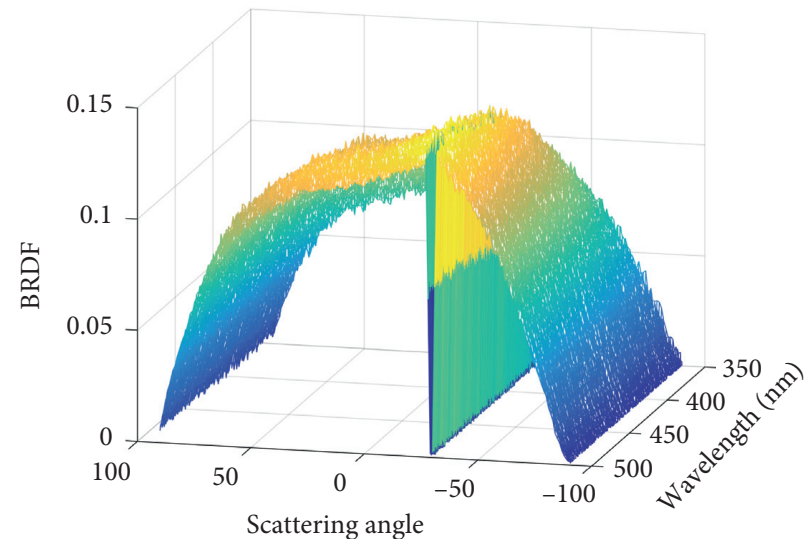

(b)

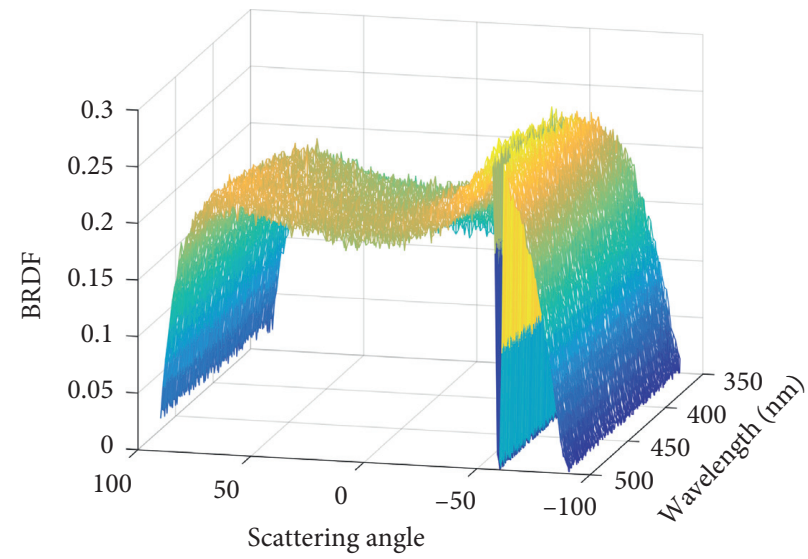

(d)

Figure 7: 3D graph of sample 4. (a) 3D data of $0^{\circ}$ incident angle; (b) $3 \mathrm{D}$ data of $30^{\circ}$ incident angle; (c) $3 \mathrm{D}$ data of $45^{\circ}$ incident angle; (d) $3 \mathrm{D}$ data of $60^{\circ}$ incident angle.

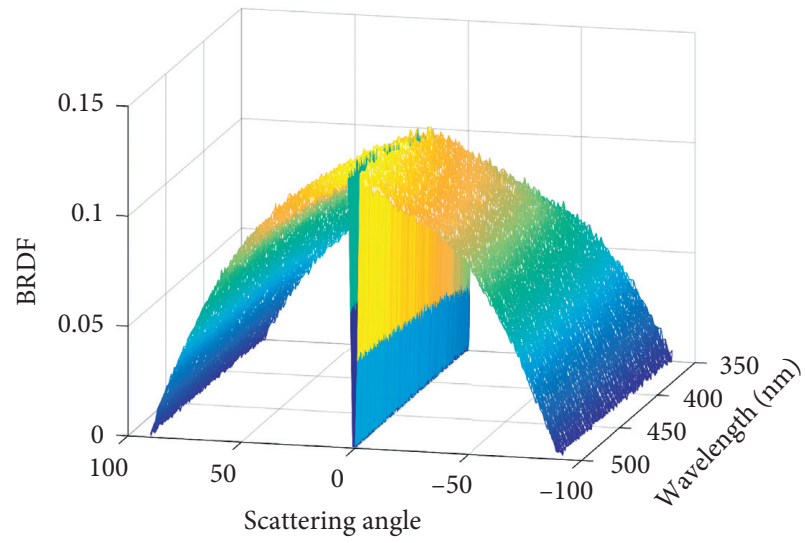

(a)

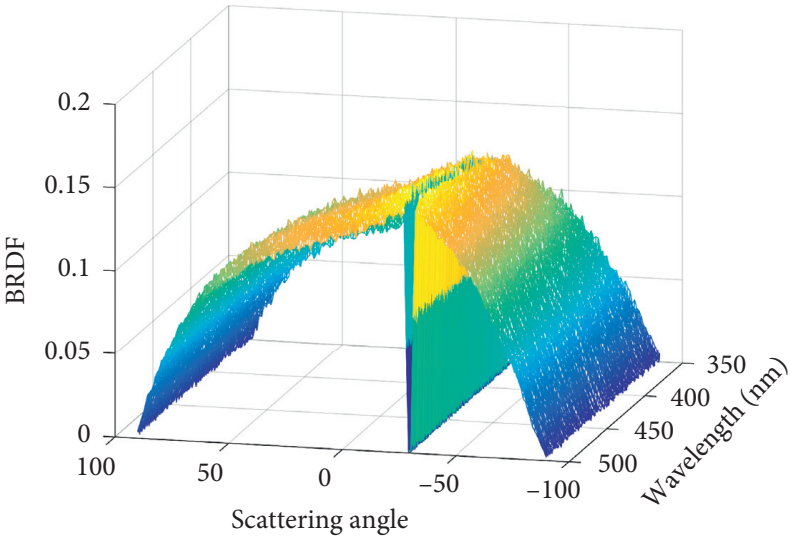

(b)

Figure 8: Continued. 


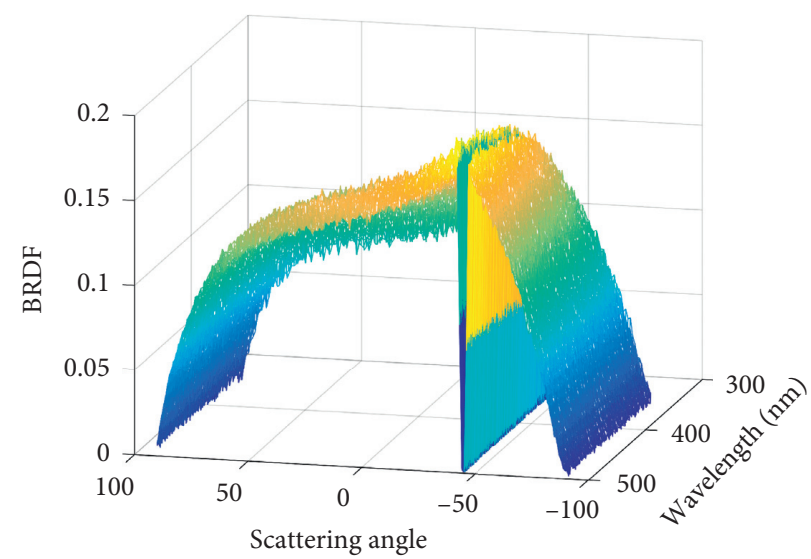

(c)

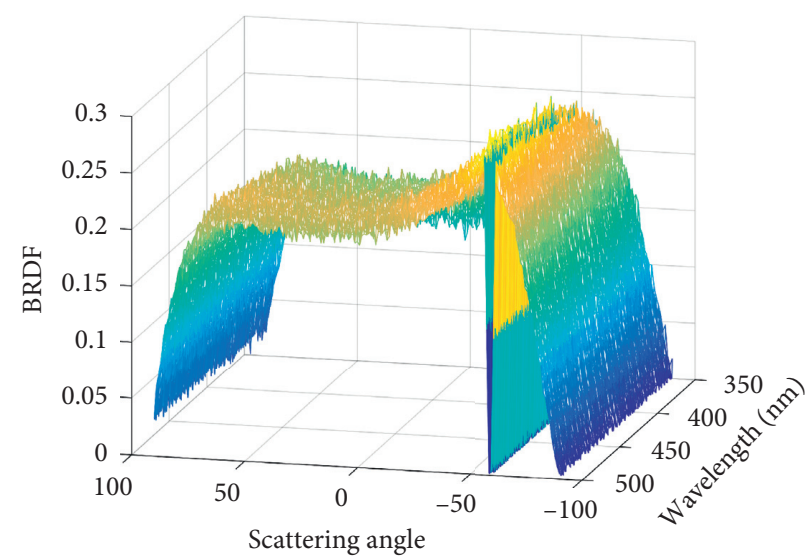

(d)

Figure 8: 3D graph of sample 5. (a) 3D data of $0^{\circ}$ incident angle; (b) $3 \mathrm{D}$ data of $30^{\circ}$ incident angle; (c) $3 \mathrm{D}$ data of $45^{\circ}$ incident angle; (d) $3 \mathrm{D}$ data of $60^{\circ}$ incident angle.

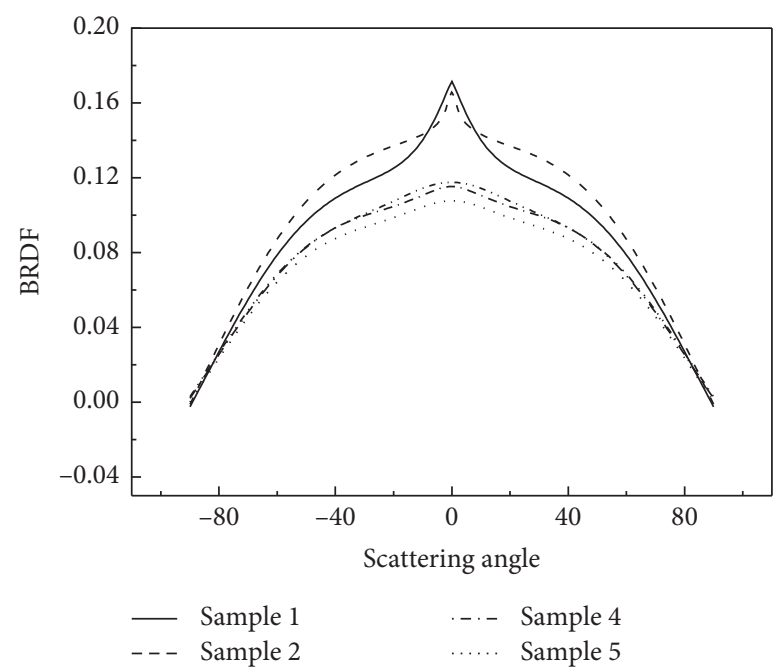

(a)

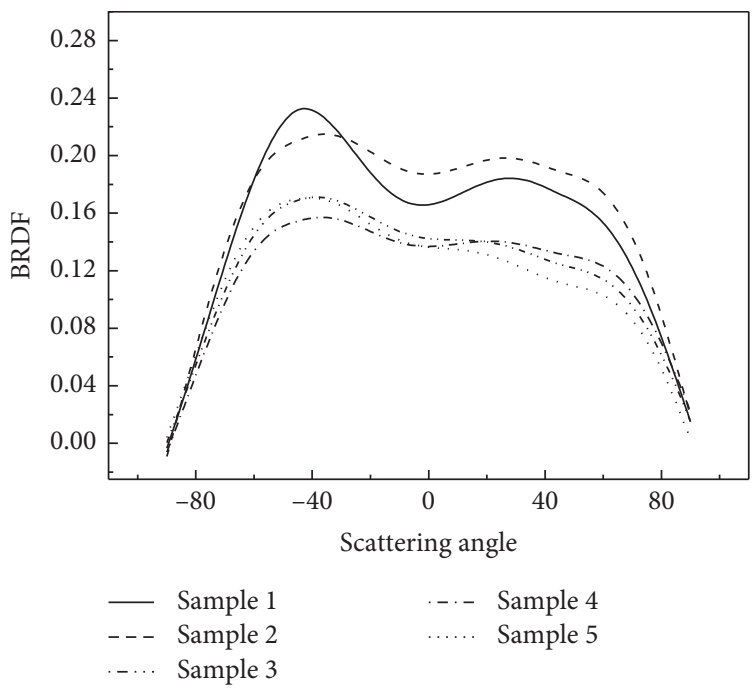

(c)

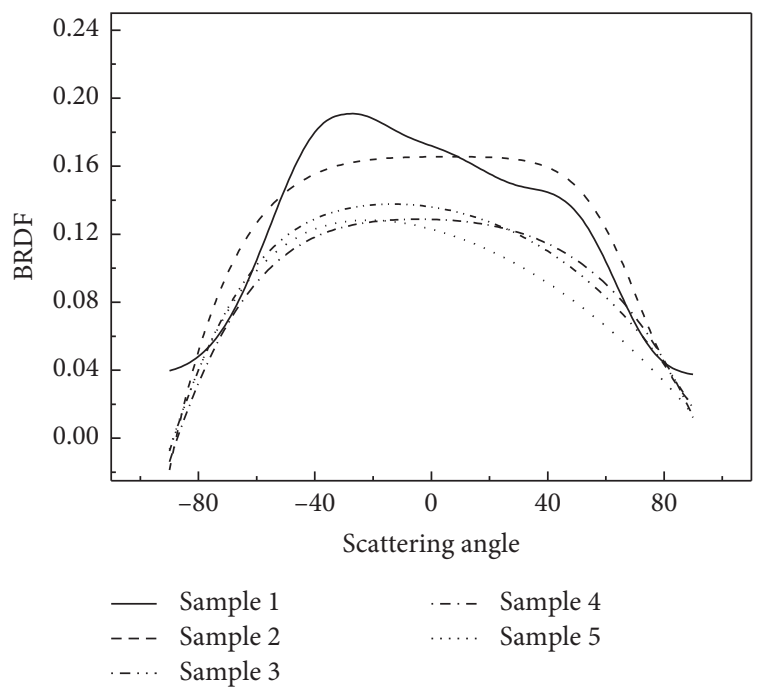

(b)

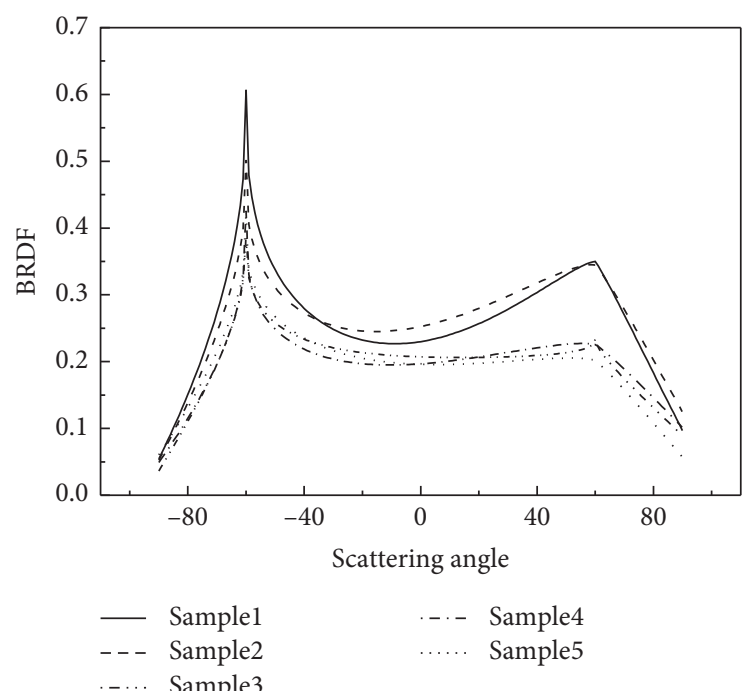

(d)

FIgURE 9: Fitted curves of Mars soil BRDF and Earth sand BRDF. (a) Fitted curve of $0^{\circ}$ incident angle; (b) fitted curve of $30^{\circ}$ incident angle; (c) fitted curve of $45^{\circ}$ incident angle; (d) fitted curve of $60^{\circ}$ incident angle. 


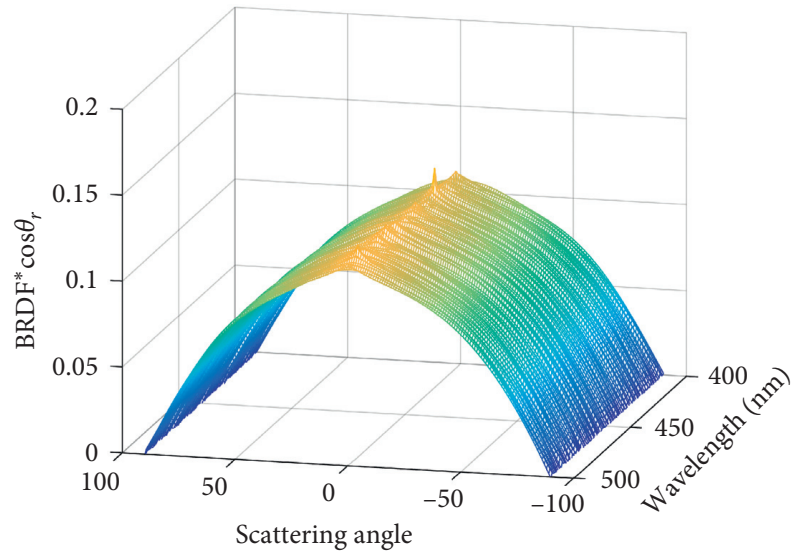

(a)

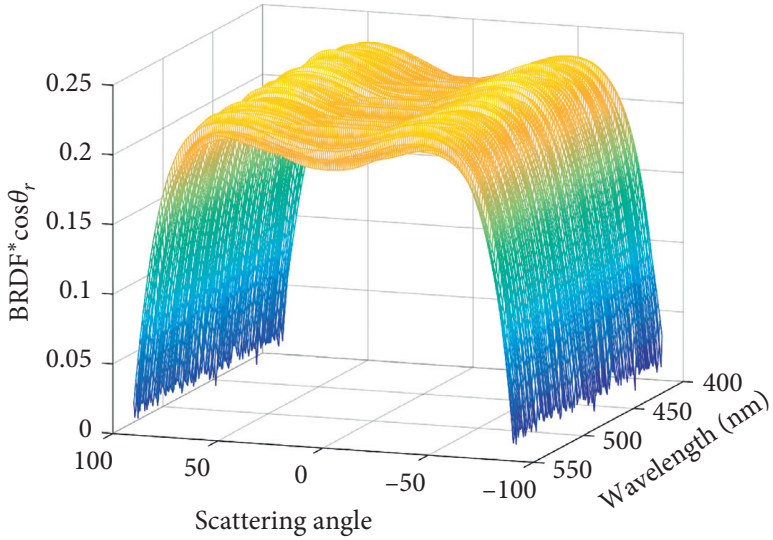

(c)

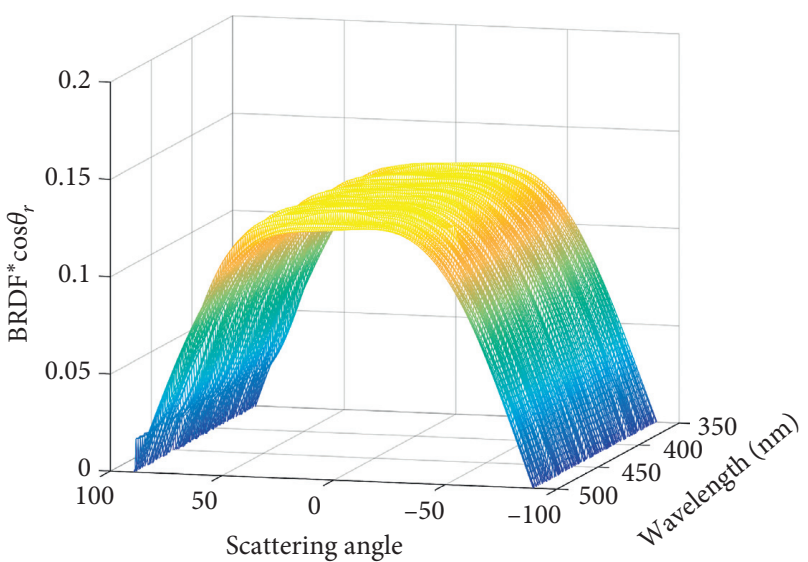

(b)

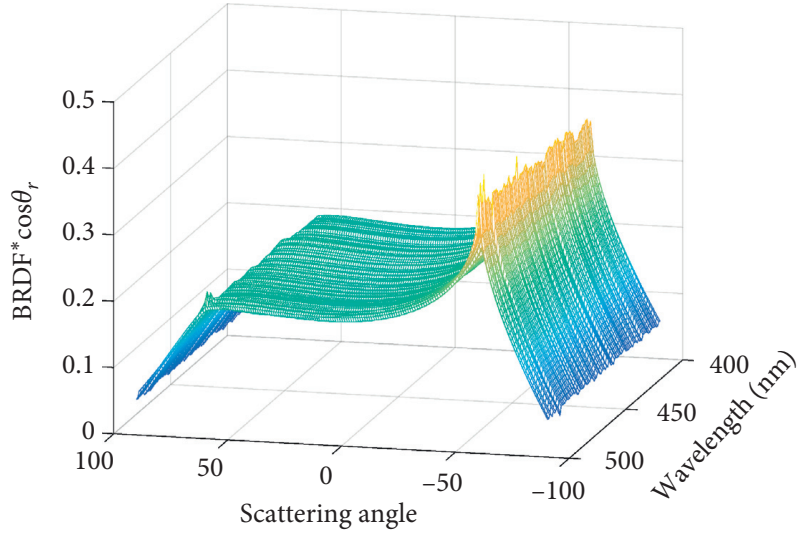

(d)

Figure 10: Fitted 3D graph of sample 2. (a) Fitted 3D graph of the $0^{\circ}$ incident angle; (b) fitted 3D graph of the 30 incident angle; (c) fitted 3D graph of the $45^{\circ}$ incident angle; (d) fitted 3D graph of the $60^{\circ}$ incident angle.

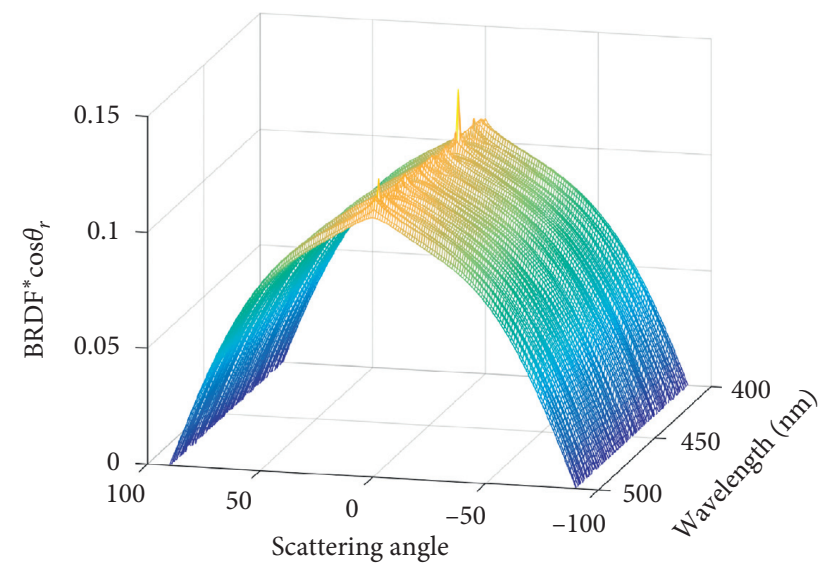

(a)

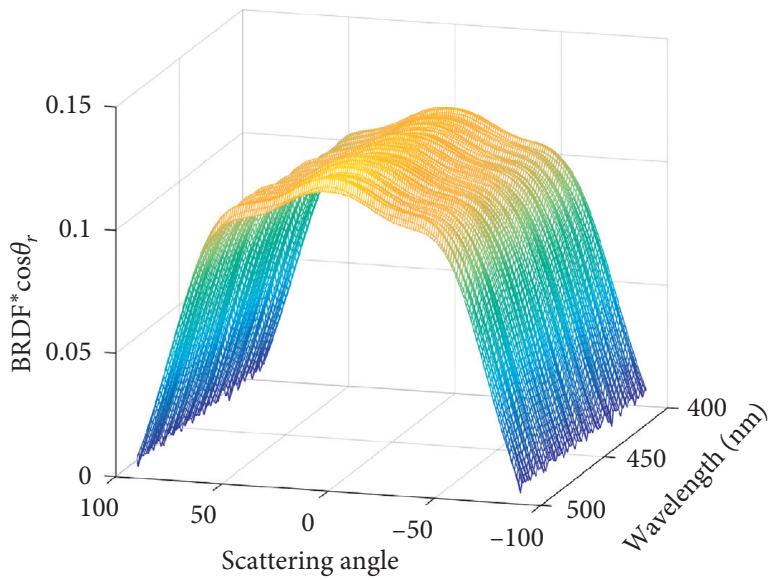

(b)

Figure 11: Continued. 


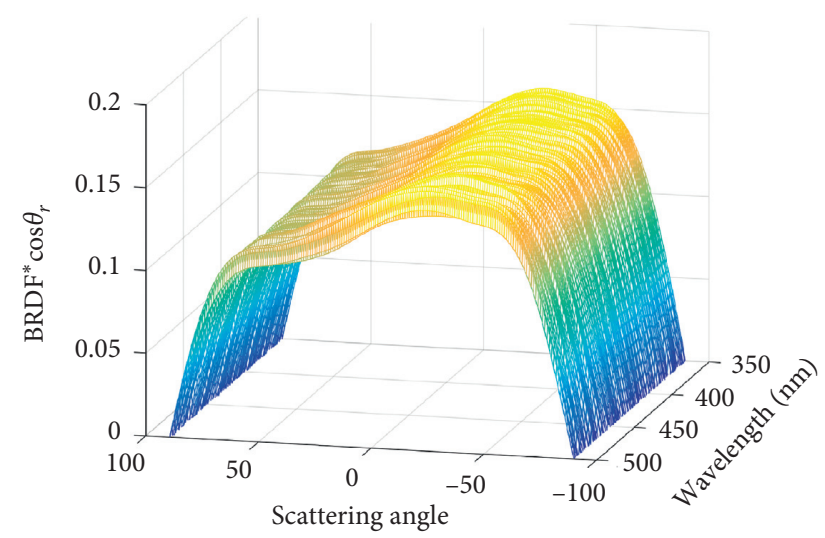

(c)

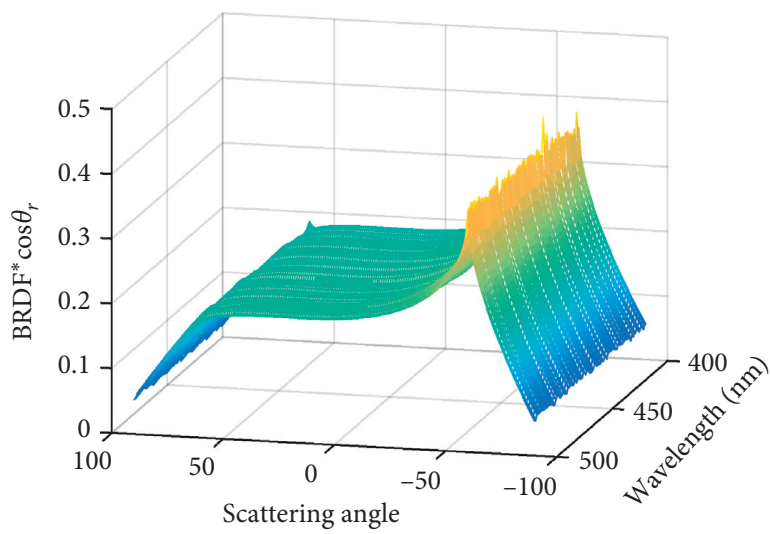

(d)

Figure 11: Fitted 3D graph of sample 3. (a) Fitted 3D graph of the $0^{\circ}$ incident angle; (b) fitted 3D graph of the 30 incident angle; (c) fitted 3D graph of the $45^{\circ}$ incident angle; (d) fitted $3 \mathrm{D}$ graph of the $60^{\circ}$ incident angle.

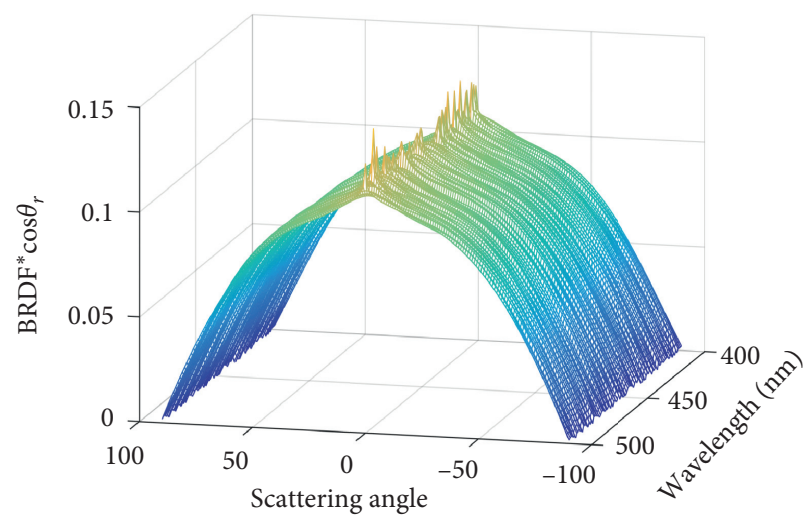

(a)

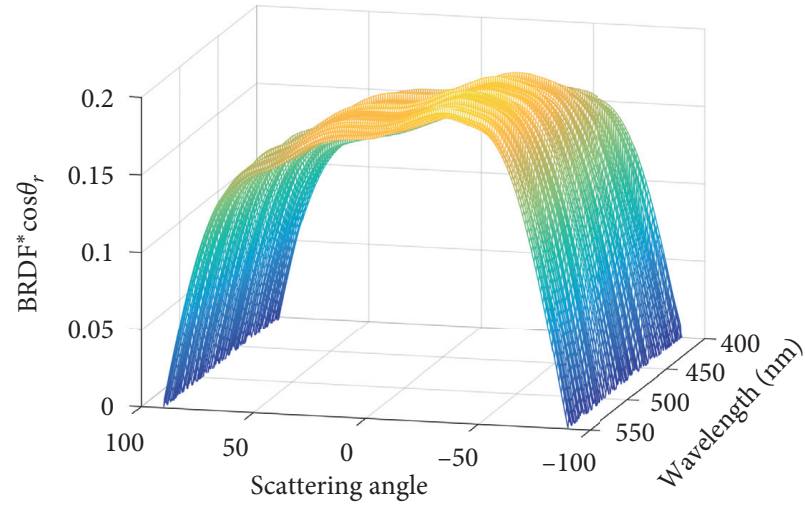

(c)

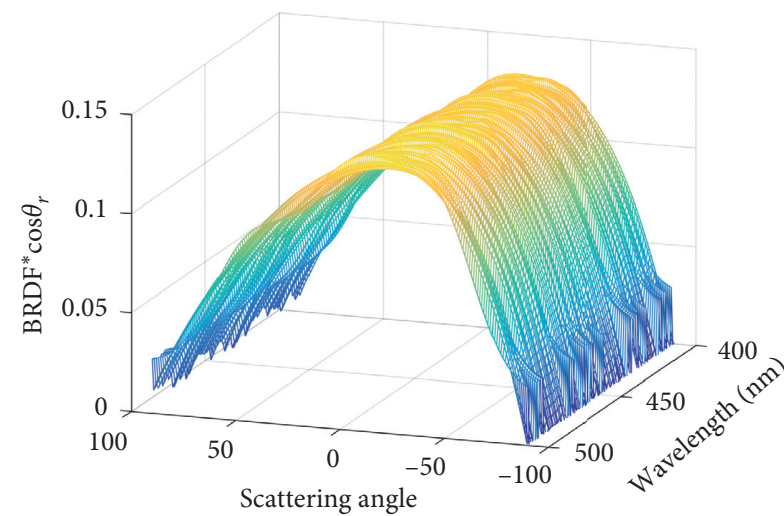

(b)

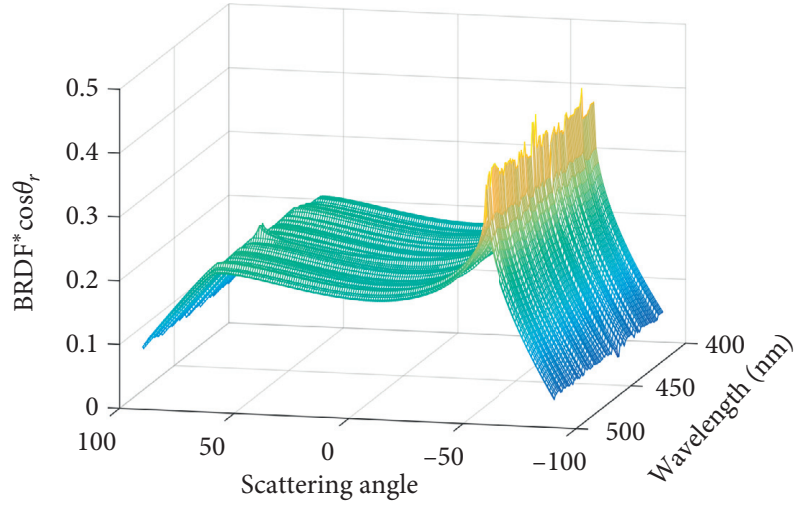

(d)

FIGURE 12: Fitted 3D graph of sample 4. (a) Fitted 3D graph of the $0^{\circ}$ incident angle; (b) fitted 3D graph of the $30^{\circ}$ incident angle; (c) fitted 3D graph of the $45^{\circ}$ incident angle; (d) fitted 3D graph of the $60^{\circ}$ incident angle. 


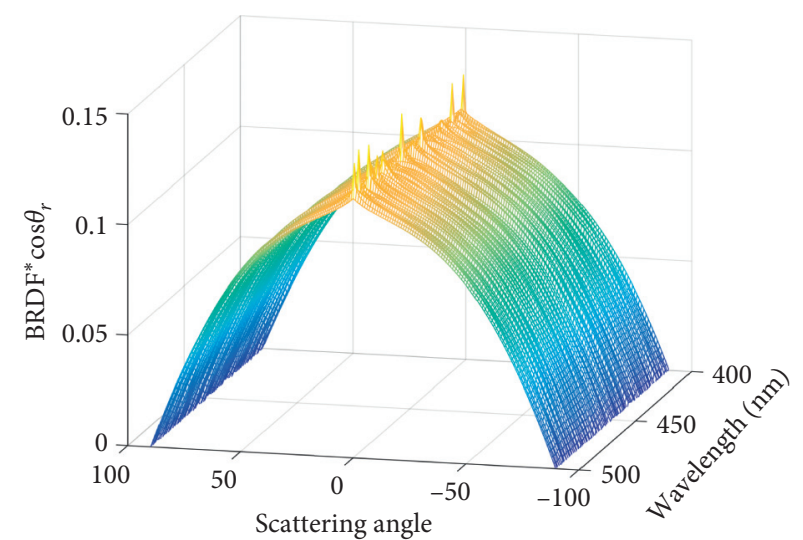

(a)

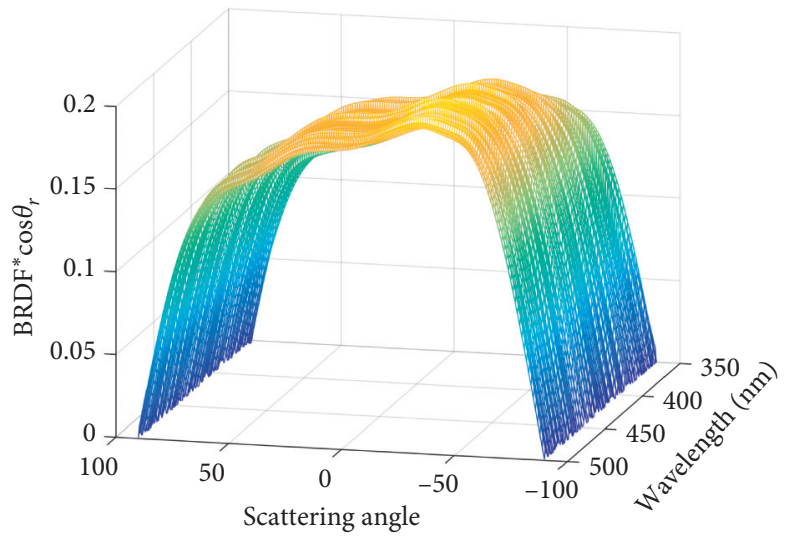

(c)

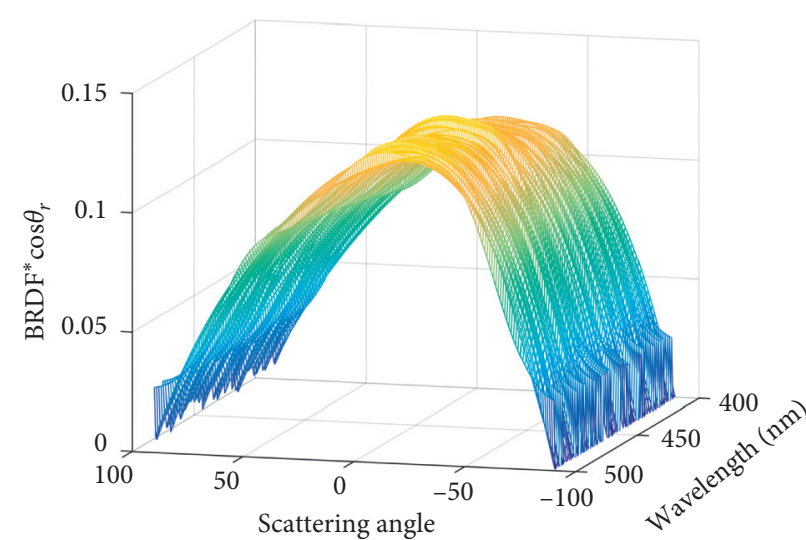

(b)

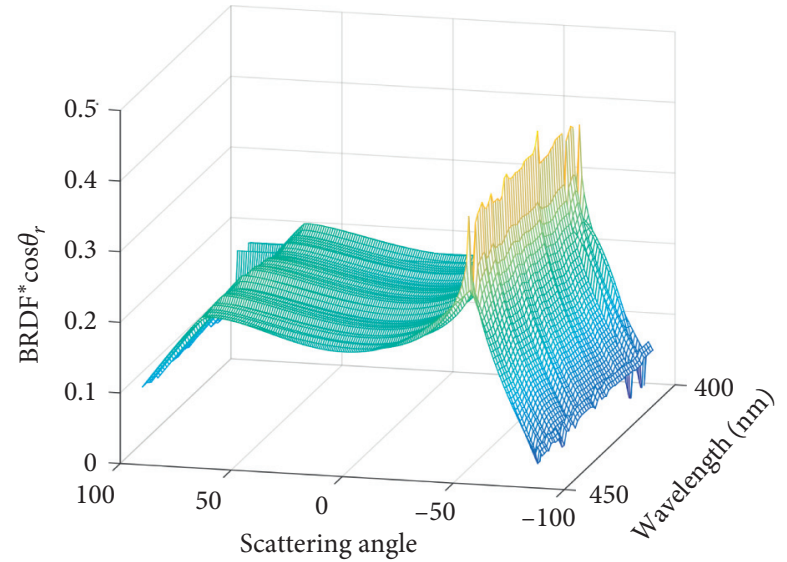

(d)

Figure 13: Fitted 3D graph of sample 5. (a) Fitted 3D graph of the $0^{\circ}$ incident angle; (b) fitted 3D graph of the 30 incident angle; (c) fitted 3D graph of the $45^{\circ}$ incident angle; (d) fitted $3 \mathrm{D}$ graph of the $60^{\circ}$ incident angle.

TABLE 1: Model parameters and errors of sample 2 to sample 5 when the incident angle is $60^{\circ}$.

\begin{tabular}{lcccccccc}
\hline & $k_{a}$ & $k_{1}$ & $a$ & $k_{b}$ & $k_{2}$ & $b$ & $k_{c}$ & Error $(\%)$ \\
\hline Sample 2 & -0.79986 & -0.71077 & 0.21686 & 1 & 1.24662 & 0.62287 & 0.41292 & 4.23 \\
Sample 3 & -0.84932 & -0.57459 & 0.24296 & 1 & 0.6747 & 0.62641 & 0.29012 & 3.85 \\
Sample 4 & -0.93863 & -0.49138 & 0.20187 & 1 & 0.64304 & 0.62416 & 0.3294 \\
Sample 5 & -0.95339 & -0.40205 & 0.22296 & 1 & 0.57859 & 0.68444 & 0.33606 & 3.13 \\
\hline
\end{tabular}

\section{Conclusion}

In this paper, a BRDF seven-parameter semiempirical statistical model suitable for the double-peak characteristic of the target BRDF data is used to fit the BRDF data of the Martian soil, which is compared with the Earth sand BRDF. The model can accurately fit the BRDF data of Martian soil, and the fitting effect is good, which is basically consistent with the original data. It provides a good basis for the subsequent research on the BRDF characteristics. In the process of comparison with the Earth sand BRDF, we find that the double-peak characteristics of Martian soil are more obvious under the same roughness conditions, and the model fitting effect is good. With the increase of roughness, the double-peak characteristic of the sand sample is little weakened, but the model can still be accurately fitted, and the model performance is superior.

\section{Data Availability}

The sandy soil BRDF data used to support the findings of this study were supplied by Shanghai Research Institute and so cannot be made freely available.

\section{Conflicts of Interest}

The authors declare that there are no conflicts of interest regarding the publication of this article.

\section{Acknowledgments}

Thanks are due to Wang Biao in 802 Institute for carrying out data measurement for this study. This work was supported by the National Natural Science Foundation of China (61405157), the National Natural Science Foundation of China (2019JQ- 
901), and Key Industry Innovation Chain Project of Shaanxi Province (2017ZDCXL-GY-06-01).

\section{References}

[1] X. Liu and L. Jiang, "Research on soil mechanical properties of martian surface soil," Journal Manned Spaceflight, vol. 22, no. 4, pp. 459-465, 2016.

[2] Z. Dang and B. Chen, "Analysis on physical and mechanical properties of martian soil," Journal of Deep Space Exploration, vol. 3, no. 2, pp. 129-133, 2016.

[3] H. Han, J. LI, B. Chen et al., "Experiment of impact performance of space lander footpad," Journal of Jilin University (Engineering and Technology Edition), vol. 47, no. 4, pp. 1194-1200, 2017.

[4] C. Jiang, Multi-angle Observation Method and Soil Reflectivity Modeling, University of Chinese Academy of Sciences, Beijing, China, 2014.

[5] X. Huang, Study on Light Scattering Characteristics of Bare Surface over Rugged Terrain, Xidian University, Xi'an, China, 2015.

[6] D. Liu, Y. Zhao, C. Chao et al., "Effects of spectral polarimetric BRDF by soil," Journal Infrared and Laser Engineering, vol. 40, no. 2, pp. 293-298, 2011.

[7] Y. Liu, Analysis of Influence Factors of Soil Polarized Heat Radiation Characteristics, Northeast Normal University, Changchun, China, 2016.

[8] J. Cheng, W. Ji, Y. Zhou et al., "Soil bidirectional reflectance characteristics as affected by soil moisture," Journal Acta Pedological Sinica, vol. 48, no. 2, pp. 255-262, 2011.

[9] Y. Liu, Y. Yao, and Si Haiqing, "Study on characteristics of hyperspectral bidirectional reflection under different soil moisture conditions," Journal of Agricultural Resources and Regional Planning, vol. 38, no. 1, pp. 51-58, 2017.

[10] T. Wu, Quantitative Relationship between Multi-Angle Polarized Reflectance and BRDF, Northeast Normal University, Changchun, China, 2006.

[11] J. Cierniewski, A. Karnieli, I. Herrmann, S. Królewicz, and K. Kuśnierek, "Soil surface illumination at micro-relief scale and soil BRDF data collected by a hyperspectral camera," International Journal of Remote Sensing, vol. 31, no. 8, pp. 2151-2157, 2010.

[12] H. Croft, K. Anderson, and N. J. Kuhn, "Reflectance anisotropy for measuring soil surface roughness of multiple soil types," Catena, vol. 93, no. 6, pp. 87-96, 2012.

[13] Z. Wang, C. A. Coburn, X. Ren, and P. M. Teillet, "Effect of surface roughness, wavelength, illumination, and viewing zenith angles on soil surface BRDF using an imaging BRDF approach," International Journal of Remote Sensing, vol. 35, no. 19, pp. 6894-6913, 2014.

[14] Z. Huang, Study on Surface Soil Water Inversion Method in Arid/semi-Arid Areas Based on Multi-Source Remote Sensing Data, South China Agricultural University, Guangzhou, China, 2016.

[15] Y. Liu, Hyperspectral Inversion of Soil Moisture Content Based on Hapke Model, Chinese Academy of Agricultural Sciences, 2017.

[16] D. L. T. N. Rosa, A. Z. Miller, R. J. M. De 1 et al., "Cellular responses of the lichen circinaria gyrosain mars-like conditions," Journal Frontiers in Microbiology, vol. 9, p. 308, 2018.

[17] L. Cheng and C. Li, "Revisiting impossible differentials of MARS-like structures," IET Information Security, vol. 11, no. 5, pp. 273-276, 2017.
[18] M. Oelsch, D. V. Opdenbosch, and E. Steinbach, "Survey of visual feature extraction algorithms in a mars-like environment," in Proceedings of the IEEE International Symposium on Multimedia, vol. 1, pp. 322-325, Taichung, Taiwan, December 2017.

[19] H. Liu, Y. Pan, J. Cao, Y. Zhou, and H. Wang, "Positivity and stability analysis for fractional-order delayed systems: a T-S fuzzy model approach," IEEE Transactions on Fuzzy Systems, p. 1, 2020.

[20] X. Huang, B. Ye, and Z. Wu, "BRDF model of bare surface over rugged terrian," Acta Optica Sinica, vol. 36, no. 1, pp. 266-273, 2016.

[21] C. K. Gatebe and M. D. King, "Airborne spectral BRDF of various surface types (ocean, vegetation, snow, desert, wetlands, cloud decks, smoke layers) for remote sensing applications," Remote Sensing of Environment, vol. 179, no. 15, pp. 131-148, 2016.

[22] C. Jiang and J. Song, "An ultrahigh-resolution digital image sensor with pixel size of $50 \mathrm{~nm}$ by vertical nanorod arrays," Advanced Materials, vol. 27, no. 30, pp. 4454-4460, 2015.

[23] F. Lu, X. Chen, I. Sato, and Y. Sato, "SymPS: BRDF symmetry guided photometric stereo for shape and light source estimation," IEEE Transactions on Pattern Analysis and Machine Intelligence, vol. 40, no. 1, pp. 221-234, 2018.

[24] M. Chandraker, "The information available to a moving observer on shape with unknown, isotropic BRDFs," IEEE Transactions on Pattern Analysis and Machine Intelligence, vol. 38, no. 7, pp. 1283-1297, 2016.

[25] Y.-F. Yang, W.-S. Li, and H.-Z. Zhang, "A seven-parameter BRDF model with double-peak characteristic suitable for sandy soil," Mathematical Problems in Engineering, vol. 2018, no. 3, 8 pages, Article ID 9398608, 2018. 